\title{
O SABER PSI INTERGERACIONAL: CRIANÇAS E ADOLESCENTES APRENDENDO COM O ESTATUTO DO IDOSO
}

\author{
Letícia Rodrigues da Silva Santos ${ }^{1}$ \\ Bárbara Cossettin Costa Beber Brunini ${ }^{2}$
}

SANTOS, L. R. da S.; BRUNINI, B. C. C. B. O saber psi intergeracional: crianças e adolescentes aprendendo com o estuto do idoso. EDUCERE Revista da Educação, Umuarama, v. 17, n. 1, p. 7-22, jan./jun. 2017

RESUMO: O presente relato de experiência objetiva descrever a vivência do Estágio Obrigatório realizado durante o quarto ano letivo do curso de Psicologia da Universidade Paranaense (UNIPAR). O Centro de Referência de Assistência Social (CRAS), na cidade de Altônia-PR, foi o primeiro aparelho articulado da rede e o disparador para que os outros aparelhos e políticas públicas fossem conectadas na realização do estágio. Neste trabalho tivemos a intenção de problematizar as vivências intergeracionais, entendidas enquanto necessidade no contexto de transformações históricas, sociais e culturais aceleradas, para possibilitar a reflexão sobre a constituição da convivência e dos laços intergeracionais e o modo como eles atravessam constantemente o cotidiano, através de famílias chefiadas por idosos, convivência entre avós e netos, e outras situações que colocam crianças, adolescentes e idosos frente a frente diariamente, não olvida-se que as diferenças geracionais estão na base do processo de transmissão sociocultural.

PALAVRAS-CHAVE: Crianças e Adolescentes; Idosos; Intergeracional.

\section{THE KNOWING PSI INTERGENERATIONAL: CHILDREN AND ADOLESCENTS LEARNING WITH THE STATUTE OF THE ELDERLY}

\footnotetext{
ABSTRAT: This report aims to describe the experience of Mandatory DOI: https://doi.org/10.25110/educere.v17i1.2017.6279

${ }^{1}$ Acadêmica do curso de Psicologia, Universidade Paranaense. Rua Alberto Jackson Byington, 276, Centro, Altônia-PR CEP: 87550-000. E-mail: le_rodrigues_s@live.com

${ }^{2}$ Mestre em Psicologia e Sociedade. Docente do curso de Psicologia, Universidade Paranaense. Rua Bartira, 2745. Umuarama-PR CEP: 87501-440. E-mail: barbrunini@prof.unipar.br
} 
Stage held during the fourth school year of Psychology Course at the Universidade Paranaense (UNIPAR). The Social Assistance Reference Center (CRAS) in Altônia-PR was the first unit of the network device and the trigger to the other public systems and policies were articulated in the realization stage. In this paper we discuss intergenerational experiences. In the context of historical, social and cultural change accelerated, rethinks the constitution of living and intergenerational ties, they constantly go through the everyday life, through families headed by elderly people, coexistence between grandparents and grandchildren, and other situations that put children, adolescents and elderly people face to face daily, do not forgets that generational differences are the basis of the socio-cultural transmission process.

KEYWORDS: Adolescents; Intergenerational; The elderly people.

\section{EL SABER PSI INTERGENERACIONAL: NIÑOS Y ADOLESCENTES APRENDIENDO CON EL ESTATUTO DEL ANCIANO}

RESUMEN: Este artículo ha buscado describir la experiencia de Pasantía Obligatoria realizada durante el cuarto año del curso de Psicología de la Universidad Paranaense (UNIPAR). El Centro de Referencia de Asistencia Social (CRAS), en la ciudad de Altônia-PR, fuel el primer sistema articulado de la red y el detonante para que otros sistemas y políticas públicas fuesen conectados en la realización de pasantía. En este estudio tuvimos la intención de problematizar las experiencias intergeneracionales, entendidas como necesidades en el contexto de transformaciones históricas, sociales y culturales aceleradas, para posibilitar la reflexión sobre la constitución de convivencia y de los vínculos intergeneracionales, la forma como ellos atraviesan constantemente el cotidiano, a través de familias encabezadas por ancianos, convivencia entre abuelos y nietos y otras situaciones que ponen niños, adolescentes y ancianos cara a cara diariamente, no olvidándose que las diferencias generacionales están en la base del proceso de transmisión sociocultural.

PALABRAS CLAVE: Ancianos; Intergeneracional; Niños y Adolescentes. 


\section{INTRODUÇÃO}

A experiência que será relatada neste artigo foi realizada no Estágio Supervisionado Curricular Obrigatório Específico I, proposta pelo curso de Psicologia da Universidade Paranaense - UNIPAR, campus SEDE Umuarama - PR, a partir de um convênio estabelecido com o Centro de Referência de Assistência Social (CRAS), da cidade de Altônia $-\mathrm{PR}$.

Através do aparelho inicial - CRAS - a rede começou a ser articulada com um trabalho que problematiza as relações intergeracionais entre crianças, adolescentes e idosos. A prática de estágio aconteceu no Centro da Juventude do município de Altônia com as crianças e adolescentes que participam do Serviço de Convivência e Fortalecimento de Vínculos (S.C.F.V).

O objetivo da prática de estágio foi trabalhar com a proposta de Psicologia Jurídica na promoção de saberes quanto aos direitos prescritos por lei destinados à população idosa. As crianças e adolescentes do S.C.F.V foram convidadas a participar de um ciclo de palestras, entrevistas e outras atividades que problematizam os direitos dos idosos respaldados no Estatuto do Idoso (2004) e articulados pelas políticas SUAS e SUS por meio dos aparelhos CRAS, CREAS (Centro de Referência Especializado em Assistência Social), NASF (Núcleo de Apoio de Saúde a Família) e Centro da Juventude.

As atividades procuraram trazer informações geracionais com os idosos asilados do Lar São Francisco de Assis da cidade de Altônia - PR., levando-os a conhecer, refletir e problematizar sobre os seus direitos expressos mediante a lei; Para tanto pautou-se em atividades deste projeto de intervenção diante a proposta de reconstrução de sua história e comunicação entre à diversidade de gerações, fortalecendo assim a sua importância histórica social como membro da comunidade onde se faz inserido, promovendo o contato da/o idosa/o com outras gerações usuárias do CRAS (Centro de Referência da Assistência Social) para que sejam disparadores de suas histórias e conhecimentos adquiridos no decorrer do projeto. 


\section{METODOLOGIA}

Frente a um vasto conjunto de determinações, leis, resoluções sobre o direito e os cuidados dos idosos, foi realizado uma breve pesquisa documental que viesse ao encontro de nossas indagações. Documentos produzidos com seriedade e beleza, todavia, nem sempre vivenciados por aquele que realmente dele deveria usufruir.

Igualmente é interesse do presente estudo, o levantamento bibliográfico que pudesse alimentar teoricamente os nossos ensaios sobre o tema pesquisado, como também que fortalecem o nosso fazer Psi. A prática de nossas intervenções envolveu pesquisa qualitativa e observação participante.

Minayo (2010), define que a pesquisa qualitativa responderá questões particulares e pertinentes. Ocupa-se, dentro das ciência sociais de uma realidade que não pode ser quantificada, medida, esta pesquisa não se baseia no critério numérico para garantir sua representatividade. Dentro desse contexto, é trabalhado com o universo dos sentidos, atitudes, valores e significados que os sujeitos dão aos fenômenos.

De acordo com a autora supracitada, uma "pergunta importante neste item é "quais indivíduos sociais têm uma vinculação mais significativa para o problema a ser invesigado? A amostragem boa é aquela que possibilita abranger a totalidade do problema investigado em suas múltiplas dimensões" (MINAYO, 2010, p. 43).

A técnica de observação participante se realiza através do contato direto do pesquisador com o fenômeno observado para obter informações sobre a realidade dos atores sociais em seus próprios contextos. O observador, enquanto parte do contexto de observação, estabelece uma relação face a face com os observados. Nesse processo, ele, ao mesmo tempo, pode modificar e ser modificado pelo contexto. A importância dessa técnica reside no fato de podermos captar uma variedade de situações ou fenômenos que não são obtidos por meio de perguntas, uma vez que, observados diretamente na própria realidade, transmitem o que há de mais imponderável e evasivo na vida real (MINAYO, 2010, p. 59).

As questões centrais da observação participante relacionam-se 
aos principais momentos da pesquisa e do projeto. Entre esses momentos está à entrada em campo pelo pesquisador, a sua capacidade de empatia e de observação, a aceitação por parte do grupo, fatores decisivos para desenvolvimento das atividades pré-planejadas.

\section{AS POLÍTICAS PÚBLICAS, OS APARELHOS E O OLHAR SO- BRE O IDOSO}

\section{SUAS - Proteção Social Básica e Proteção Social Especializada}

Em 2003 ocorreu a IV Conferência Nacional de Assistência Social, que a partir das suas deliberações e das diretrizes estabelecidas pela Lei Orgânica de Assistência Social - LOAS (1993), foi aprovada a implementação do Sistema Único de Assistência Social - SUAS.

O SUAS operaliza a Política Nacional de Assistência Social PNAS (2004), que propõe um projeto político responsável por reestruturar a gestão da Assistência Social. As ações nesta nova política estão conectadas com os territórios, sujeitos e direitos desses. É um olhar responsável pelo proteção, prevenção e promoção da vida. A equipe mínima do SUAS composta por psicólogas/os e assistente social precisa estar atentas às vulnerabilidades presentes nos territórios e comunidades. Para isso, é preciso ir até campo, estar onde as famílias e sujeitos estabelecem seus maiores vínculos e, 'entrar' na vida desses, não como invasão, mas sim com a intenção de compreender as vivências dos usuários dessa política.

De acordo com CREPOP (2008) o SUAS é composto por duas grandes estruturas articuladas entre si, a Proteção Social Básica, que acontece por meio do aparelho CRAS e a Proteção Social Especial que irá ocorrer mediante o aparelho CREAS, pois dentro dos territórios existirão ações de média e alta complexidade.Segundo PNAS (2004) apud CREPOP (2008) a Proteção Social Básica tem como objetivos:

[...] situações de risco por meio do desenvolvimento de potencialidades e aquisições, e o fortalecimento de vínculos familiares e comunitários. Destina-se à população que vive em situação de vulnerabilidade social decorrente da pobreza, privação (ausência de renda, precário ou nulo acesso aos serviços pú- 
blicos, dentre outros) e ou fragilização de vínculos afetivos relacionais e de pertencimento social (discriminações etárias, étnicas, de gênero ou por deficiências, dentre outras) (PNAS, 2004, p.27).

A proteção social básica articula ações de prevenção dentro dos territórios, por meio do desenvolvimento de potencialidades e fortalecimento de vínculos, quando identificado casos que implicam violação de direitos, tais como violência sexual, física, psicológica, etc. são encaminhados para a Proteção Social Especial, que de acordo com PNSA (2004) é:

[...] uma modalidade de atendimento assistencial destinada a famílias e indivíduos que se encontram em situação de risco pessoal e social, por ocorrência de abandono, maus tratos físicos e/ou psíquicos, abuso sexual, uso de substâncias psicoativas, cumprimento de medidas socioeducativas, situação de rua, situação de trabalho infantil, entre outras (PNAS, 2004, p.28).

O CRAS por meio da Proteção Social Básica oferece aos idosos dentro de sua política serviços de fortalecimento de vínculos e que proporcionam a esses um contato e vivência geracional e atividades que promovem o bem-estar biopsicossocial, serviços como a carteirinha do idoso, benefício de previdência continuada, e outras ações de promoção e prevenção da qualidade de vida de idosos/as. O CREAS por meio da Proteção Social Especializada, desenvolve seu trabalho com idosos em situação de vulnerabilidade, em que seus direitos foram violados, como nos casos de violência, seja de cunho físico, psicológico, financeiro, sexual, entre outras violências, maus tratos, negligência, discriminação, etc.

\section{SUS - NASF (Núcleo de Apoio a Saúde da Família) e Saúde da Pessoa Idosa}

O Sistema Único de Saúde - SUS foi criado em 1988 pela Constituição Federal Brasileira e, é o sistema de saúde unificado, integral e gratuito que trabalha com o conceito ampliado de saúde. Esse sistema 
abrange toda a população brasileira e é um dos maiores do mundo (MINISTÉRIO DA SAÚDE, s/ano).

O NASF foi criado pelo Ministério da Saúde mediante a Portaria $\mathrm{n}^{\circ} 154$ de 24 de Janeiro de 2008, republicada em 04 de março do mesmo ano. O principal objetivo, de acordo com as diretrizes dessa política (2008), foi o de apoiar a inserção da Estratégia de Saúde da Família e da rede de serviços. "O Nasf é uma estratégia inovadora que tem por objetivo apoiar, ampliar, aperfeiçoar a atenção e a gestão da saúde na Atenção Básica/Saúde da Família" (BRASIL, 2004, p. 11), o NASF também amplia a abrangência e o escopo de ações da Atenção Básica:

[...] é aumentar a resolutividade dela, reforçando os processos de territorialização e regionalização em saúde. A referida Portaria traz como pressupostos políticas nacionais diversas, tais como: de Atenção Básica; de Promoção da Saúde; de Integração da Pessoa com Deficiência; de Alimentação e Nutrição; de Saúde da Criança e do Adolescente; de Atenção Integral à Saúde da Mulher; de Práticas Integrativas e Complementares; de Assistência Farmacêutica; da Pessoa Idosa; de Saúde Mental; de Humanização em Saúde, além da Política Nacional de Assistência Social e da Saúde do Homem. (BRASIL, 2004, p. $10)$.

$\mathrm{O}$ atendimento ao idoso na saúde é assegurado pelo Capítulo IV do Estatuto do Idoso (2003), que discorre que idosas/os têm de possuir atenção integral à saúde, por intermédio do SUS, "garantindo-lhe o acesso universal e igualitário, em conjunto articulado e contínuo das ações e serviços, para a prevenção, promoção e recuperação da saúde, incluindo a atenção especial às doenças que afetam preferencialmente os idosos". (BRASIL, 2003, p. 14).

\section{Serviço de Convivência e Fortalecimento de Vínculos para Criança e Adolescentes - SCFV}

O SCFV é um serviço do SUAS articulado pela Proteção Social Básica - CRAS e é ofertado para completar o Serviço de Proteção e Atendimento Integral às Famílias - PAIF e o Serviço de Proteção e Aten- 
dimento Especializado às Famílias e Indivíduos - PAEFI. Nesse serviço (SCFV) é realizado atendimentos em grupos, em que atividades culturais, artísticas, esportivas e de lazer são realizadas com crianças e adolescentes entre 06 e 16 anos de idade.

O objetivo do serviço é criar intervenções sócias que estimulem e orientem as crianças e adolescentes usuárias na construção de suas vivências individuais e coletivas. Assim como articular os vínculos familiares, promover a integração e a troca de experiências entre os participantes, valorizando o sentimento de vida coletiva. O SCFV possui um caráter preventivo, pautado na defesa e afirmação de direitos e no desenvolvimento de capacidades dos usuários.

\section{Dando vida à prática por meio dos aparelhos}

As primeiras vivências com o local de estágio proporcionaram contato com vários públicos usuários das políticas públicas do CRAS e os serviços oferecidos. Durante a visita no Serviço de Convivência e Fortalecimento de Vínculos para Idosos surgiu a ideia de desenvolver um trabalho direcionado a esse público. Em conversas com a equipe mínima do CRAS e orientadora de estágio para desenvolvimento do projeto geracional com idosos, surgiu a informação que os idosos do Lar São Francisco de Assis do município de Altônia - PR não participavam do S.C.F.V - Idosos, e então a prática passou a ser direcionada a esse contexto.

A primeira articulação envolveu o S.C.F.V - Crianças e Adolescentes, pois a proposta de estágio é uma interação entre gerações, como previsto como uma das práticas da/o profissional Psi dentro do CRAS: “ 1. Serviços: socioeducativo-geracionais, intergeracionais e com famílias; sócio comunitário; reabilitação na comunidade; outros;" (BRASIL, 2007, p. 22). O trabalho envolveu as crianças e adolescentes em um movimento com propósito educacional, orientando o público alvo em relação aos direitos dos idosos e articulando a rede para que pudessem ter contato com um pouco dos aparelhos.

O projeto iniciou-se em agosto de 2015 e finalizou em novembro do mesmo ano, sendo dividido em três etapas feitas para as crianças e adolescentes e construídas com elas em participação com a estagiária. A primeira etapa do projeto envolveu um ciclo de palestras e rodas de con- 
versas com profissionais que atendem diretamente os idosos usuários do SUAS e SUS. A palestra que iniciou esse ciclo possuiu como convidadas a psicóloga do CRAS e a assistente social do CREAS, ambas compõe a equipe mínima desses dois aparelhos, exercendo funções que hora se diferenciam pelo olhar de cada ciência, hora se complementam, mesmo que estejam em locais de desenvolvimento do SUAS diferenciados, mas o trabalho em rede é essencial para que possa oferecer o mínimo de acesso e direito aos usuários.

Ao iniciar a fala, brevemente o trabalho desenvolvido no CRAS e no CREAS foi apresentado, assim como a profissão de cada uma. A proposta inicial seria que uma palestra fosse ministrada, mas as profissionais construíram junto com as crianças e adolescentes uma roda de conversa que envolveu temas presentes no dia-a-dia de trabalho nesses aparelhos, principalmente voltado aos idosos/as. Entre as temáticas, crianças e adolescentes foram orientados sobre negligência contra idosos, preconceito, discriminação e o que fazer em relação a situações que os envolva. Novamente o Estatuto do Idoso foi apresentado e discorrido o Capítulo VIII do mesmo, entre os Art. 33 a 36:

Art. 33. A assistência social aos idosos será prestada, de forma articulada, conforme os princípios e diretrizes previstos na Lei Orgânica da Assistência Social, na Política Nacional do Idoso, no Sistema Único de Saúde e demais normas pertinentes.

Art. 34. Aos idosos, a partir de sessenta e cinco anos, que não possuam meios para prover sua subsistência, nem de tê-la provida por sua família, é assegurado o benefício mensal de um salário mínimo, nos termos da Lei Orgânica da Assistência Social (Loas).

Parágrafo único. O benefício já concedido a qualquer membro da família nos termos do caput não será computado para os fins do cálculo da renda familiar per capita a que se refere a Loas. Art. 35. Todas as entidades de longa permanência, ou casa-lar, são obrigadas a firmar contrato de prestação de serviços com a pessoa idosa abrigada.

$\S 1^{\circ}$ No caso de entidades filantrópicas, ou casa-lar, é facultada a cobrança de participação do idoso no custeio da entidade. $\S 2^{\circ} \mathrm{O}$ conselho municipal do idoso ou o conselho municipal da assistência social estabelecerá a forma de participação 
prevista no $\S 1^{\circ}$, que não poderá exceder a setenta por cento de qualquer benefício previdenciário ou de assistência social percebido pelo idoso.

$\S 3^{\circ}$ Se a pessoa idosa for incapaz, caberá a seu representante legal firmar o contrato a que se refere o caput deste artigo.

Art. 36. O acolhimento de idosos em situação de risco social, por adulto ou núcleo familiar, caracteriza a dependência econômica, para os efeitos legais. (BRASIL, 2013, p. 18).

Após a conversa e atividade expositiva, as crianças e adolescentes foram convidados a participar de uma brincadeira de perguntas e respostas sobre os temas trabalhados e a dar sugestões para as próximas atividades.

A segunda palestra foi articulada pelo médico responsável pelo NASF do munícipio de Altônia-PR e também médico geriatra do mesmo município. Inicialmente o tema trabalhado foi o SUS e como em suas diretrizes possui determinações próprias de atendimento aos idosos, assim como possui para crianças e adolescentes, mas que não deixa de ser um sistema unificado e que os serviços oferecidos abrangem a todos de forma gratuita.

Um tempo para perguntas e interação foi aberta após a fala expositiva, e as crianças e adolescentes trouxeram temas voltados diretamente as suas vivências com idosos e demais curiosidades que foram surgindo ao longo da fala do médico. Doenças mais específicas dos idosos foram questionadas, tais como Alzheimer e Parkinson.

Ao fim das palestras e rodas de conversa, a segunda etapa do projeto iniciou-se com um ciclo de entrevistas feitas pelos próprios adolescentes, diferente da primeira etapa do projeto, em que os profissionais foram até o centro de convivência onde acontece o S.C.F.V - crianças e adolescentes. Agora, foram estes que foram até profissionais, para conhecer os aparelhos, suas funções, localidade e demais colaboradores da rede. Através de uma roda de conversa estruturada como uma entrevista ministrada pelos adolescentes e registradas por eles por meio de vídeos, perguntas diversas sobre os temas já trabalhados foram feitas.

Além dos aparelhos CRAS, CREAS já conhecidos anteriormente por meio da exposição das palestras, as crianças e adolescentes foram até o S.C.V.F - Idosos para participar de uma tarde interativa com eles 
e conhecer as atividades ali realizadas. Após o primeiro contato, alguns idosos/as foram convidados/as a fazerem parte das entrevistas que compõem a segunda parte do projeto. Ocorreu o interesse de quatro idosas que expuseram em falas livres como se sentem sendo idosas.

Assim, aconteceu com os demais profissionais, o médico também seria entrevistado nessa etapa, mas por erro de comunicação entre as redes e a agenda voltada aos compromissos com o "Outubro Rosa" a realização foi impossibilitada.

A terceira etapa e última foi uma visita ao Lar São Francisco de Assis do município de Altônia - PR para que os adolescentes e crianças que participaram ao longo desses três meses de projeto pudessem ter contato com aqueles que indiretamente foram os responsáveis por despertar a idealização da prática. Nesta última etapa, assim como na segunda, as crianças e adolescentes construíram as atividades desenvolvidas no lar.

Durante a visita, a maior intenção da equipe técnica do Serviço de Convivência e Fortalecimento de Vínculos, assim como das crianças e adolescentes que estavam ali, era de promover uma interação entre a realidade contemporânea deles, e ouvir dos idosos suas percepções de vida, e realizações ao longo de sua trajetória.

Escolheram ir caracterizados de palhaços e entre outros personagens de histórias infantis, para que em roda de conversa essas histórias fossem contadas aos idosos. A recepção de alguns dos idosos asilados foi um pouco ríspida, mas aos poucos foram se envolvendo nas atividades elaboradas pelas crianças e adolescentes e coordenadas pela estagiária responsável.

Experiências de uma infância diferente foram contadas e comparadas de forma descontraída e trocas de afetos foram desenvolvidas ao longo das atividades, os idosos aos poucos envolveram-se com as crianças e adolescentes, e retribuíram em mesma intensidade, ou maior.

\section{DISCUSSÃO}

Durante a prática do estágio foi possível notar que ainda existe um caminho grande a percorrer na interação entre crianças, adolescentes e idosos. Para os dois primeiros públicos o olhar que os permeia quando se pensa em idosos, é um olhar ainda voltado ao preconceito. Preconceito 
esse construído dentro da contemporaneidade e por meio do sistema capitalista que só considera aqueles sujeitos produtivos, como reproduzido na fala de adolescentes que participaram do projeto.

Ao pensar-se em Rozendo (2010) e na construção história que fez sobre a família, inicialmente percebemos que dentro das relações sociais as crianças eram os sujeitos colocados à margem e que de certa maneira não possuíam significado ativo dentro daquela sociedade. Hoje o sistema produz mecanismos que colocam às margens os idosos, e estes muitas vezes estigmatizados ou até mesmo esquecidos, como na realidade da maioria dos idosos asilados no Lar São Francisco de Assis, não possuem contato com outras gerações, e acima de tudo, acabam não possuindo o respeito dessas gerações.

Existem muitas políticas públicas responsáveis pelo olhar e cuidado da terceira idade, mas ao meu ver, não basta existir, elas precisam alcançar aqueles dos quais delas têm direito e ao longo da prática, foi possível perceber que nem todos os idosos são de fato, idosos de direitos. Percepção confirmada, quando realizada a visita aos idosos asilados. Poucos sabiam, o que era o Estatuto do Idoso, e os que sabiam, desconheciam o que esses dispositivo defendia.

Pensando em Direitos Humanos, e problematizando uma frase que sempre ouvi no senso comum, em que afirma que Direitos Humanos é para Humanos Direitos, questiono-me imediatamente então, hoje, dentro do contexto em que a prática de estágio foi realizada: devemos considerar que os idosos asilados não são humanos, ou melhor, não são humanos direitos? Afinal, são ali esquecidos pelas famílias, sociedade e acima de tudo, pelas políticas públicas. Esquecidos por elas, não por déficit da rede SUAS e SUS do município, mas por estarem fechados dentro de uma instituição, que ao pensar em Goffman (1987) podemos nomeá-la de instituição total, e ao falar-se de Foucault (2004) de instituição disciplinar.

Goffman (1987), entende por instituição total, locais os quais o sujeito permanece, durante um determinado tempo, e nele realiza todas as suas atividades. Sejam essas impostas por um sistema hierárquico que o insere ao meio, ou por vontade do próprio sujeito, quando aceita ser um corpo assujeitado por supostos ganhos afetivos nestes recintos. Para Foucault (2004), essas instituições totais, estão regidas por um sistema disciplinar que dociliza os corpos e produz comportamentos ditos "corre- 
tos" de conduta e formas de estar no mundo.

\section{CONSIDERAÇÕES FINAIS}

A Psicologia vem "escorregando" por novos territórios que constroem novos olhares além dos individualizados de práxis clínicas elitizadas, garantindo a emancipação e direitos a todos os que dele tem direitos. Os profissionais e as formações em Psicologia engajadas política e eticamente com esses novos territórios alcançados têm proporcionado práxis a profissionais e estagiárias envolvidas por um olhar crítico, ético, estético e político (FOUCALT, 1985).

A estética pode ser compreendida conforme o autor supracitado como a transformação de si como sujeito moral, descontruindo naturalização e conformação sobre as regras impostas é uma busca muitas vezes sutil pela estética da existência. Essa busca silenciosa ou não pode ser silenciada e colocada ao esquecimento pelas diversas linhas que atravessam os sujeitos e são responsáveis pelos processos de subjetivação.

O olhar ético cabe conhecer, divulgar e cumprir o código de ética do Psicólogo (2014) e basear "o seu trabalho no respeito e na promoção da liberdade, da dignidade, da igualdade e da integridade do ser humano, apoiado nos valores que embasam a Declaração Universal dos Direitos Humanos" (BRASIL, CEP, 2014, p. 7).

A postura política de psicólogas/os é descontruir o olhar elitizado que desconsiderou e ainda desconsidera o conceito de pluralidade de Arendt, citado por Azêredo (2002): o princípio humano de sermos todos iguais, humanos, mas diferentes em singularidade e modos de estar no mundo. É acreditar no sentido da política como liberdade de sempre ter a possibilidade de fazer novos começos. É conseguir construir um olhar dentro das práxis psi, principalmente, nas políticas públicas que empoderam o sujeito que as utilizam, tornando cada vez mais as pessoas cidadãs e alimentando o desejo no sujeito de ser autor de sua própria história.

As instituições totais definidas por Goffman (1987), e Foucault Instituições disciplinares, são responsáveis por agenciar as linhas de atravessamento, normas e padrões "normais" de conduta que precisam ser seguidos. Deleuze e Guattari (1995) escrevem que esses agenciamentos são uma cartografia, que no decorrer da história acabou produzindo uma 
segmentariedade endurecida das relações entre a micropolítica - corpos agenciados - e a macropolítica - poder que agencia. É papel das práticas Psi engajadas descontruir essas relações que desconsideram as diferenças, principalmente as diferenças geracionais, que na contemporaneidade, colocam o corpo idoso, como corpo as margens e de exclusão, pelas relações de saberes e poder da macropolítica, que desconsideram os agenciamentos dos corpos que não produzem e por isso não são rendáveis. $\mathrm{Na}$ lógica desse olhar se produz discursos, como: "os idosos já viveram tudo que tinham para viver", e mediante esses juízos de valores implantados desconsidera-se qualquer história de vida e construção do sujeito.

$\mathrm{Na}$ construção desse novo olhar, as mais variadas áreas da Psicologia vem se reinventando e escorregando por novos territórios antes desconsiderados. A Psicologia Jurídica é um dos exemplos dessa nova construção. Segundo França (2004, p. 74), essa área entende-se por "uma das dominações para nomear a área da Psicologia que se relaciona com o sistema da justiça", ou seja, vai além do fórum ou tribunal, vai além de ser "só" uma Psicologia Forense, "a palavra "jurídica" torna-se mais abrangente por referir-se aos procedimentos ocorridos nos tribunais, bem como àqueles que são frutos da decisão judicial ou ainda àqueles que são de interesse do jurídico ou do Direito" (Id. Ibid).

Dentro desse olhar, por que não pensar a Psicologia Jurídica dentro de ambientes que antes cabia "apenas" a Psicologia Comunitária, como o Centro de Referência de Assistência Social (CRAS) que segundo a literatura pode ser definido como: Uma unidade pública estatal presente nos munícipios e é a porta de entrada para o Sistema Único de Assistência Social (SUAS). É responsável pela oferta de serviços básicos a população, sujeito e/ou comunidade em vulnerabilidade social. O principal serviço ofertado pelo CRAS é o de Proteção e Atendimento Integral à Família (PAIF). Este é um trabalho que visa a fortalecer os vínculos com as famílias usuárias dos serviços do SUAS, promovendo a melhoria da qualidade de vida. Além dessas funções, o CRAS tem como objetivo o desenvolvimento local, potencializando o território de modo geral e seu foco de atuação é promoção e prevenção da vida (CREPOP, 2007).

E por que não ir além, pensar a/o psicóloga/o jurídico como colaborador na construção de políticas públicas, que podem ser entendidas como um conjunto de normas que orientam práticas e respaldam os direi- 
tos dos indivíduos em todos os níveis e setores da sociedade. (BRASIL, 2007, p. 23). E ir mais além, por que não pensar esse profissional trabalhando não apenas demandas já existentes, mas com práxis que trabalhem os Direitos Humanos e direitos de cada cidadão antes desses direitos de fato serem violados?

Rozengo (2010) utiliza o termo: Asilo uma política higienista, para referir-se as casas lares, asilos, casas de repouso entre outras denominações em que senhores e senhoras de idade são, muitas vezes "esquecidos", por não serem mais rendáveis ao capital, a família e outros meios sociais. Dentro dessas instituições, muitas vezes, sua estética da existência, seus processos de subjetivação são silenciados por normas de disciplinamento que procuram docificar os comportamentos que se encaixem com a realidade institucional.

A experiência vivenciada na prática do estágio específica, foi da tentativa de uma implantação do novo, do diferente. Uma tentativa de sair do que Ramos (2012) definiu como o cinismo da ciência e do comodismo e procurar enxergar a Psicologia Jurídica dentro desse novo ambiente, em que procurará por mais pequeno que seja dar voz aqueles que, muitas vezes, foram esquecidos. Resgatar suas subjetividades e formas de estar e existir que são silenciadas por mecanismos disciplinares. É procurar mesmo que situada dar direito à liberdade a esses idosos/a como previsto no estatuto do idoso Capítulo II, Art 10, que diz que o direito à liberdade compreende, entre outros, os seguintes aspectos I - faculdade de ir, vir e estar nos logradouros públicos e espaços comunitários, ressalvadas as restrições legais; II - opinião e expressão; III - crença e culto religioso; IV - prática de esportes e de diversões; V - participação na vida familiar e comunitária; VI - participação na vida política, na forma da lei; VII faculdade de buscar refúgio, auxílio e orientação.

\section{REFERÊNCIAS}

AZERÊDO, S. M. M. O político, o público e a alteridade como desafio para a psicologia. Psicologia Ciência e Profissão, v. 22, n. 4, 4, p. 1423, 2002.

BRASIL. Estatuto do idoso: lei federal no 10.741, de 01 de outubro de 2003. Brasília: Secretaria Especial dos Direitos Humanos, 2004. 
CONSELHO FEDERAL DE PSICOLOGIA. Código de ética profissional do psicólogo. Brasília: O Conselho, 2005. 18 p.

. Centro de Referências Técnicas Em Psicologia e Políticas

Públicas - CREPOP. Referência técnica para atuaçãodo(a) psicólogo(a) no CRAS/SUAS. Brasília: Conselho Federal de Psicologia. 2007.

DELEUZE, G.; GUATTARI, F. Mil platôs: capitalismo e esquizofrenia. Rio de Janeiro: Ed. 34, 1995.

FRANÇA, F. Reflexões sobre psicologia jurídica e seu panorama no Brasil. Psicologia: Teoria e Prática, v. 6, n. 1, p. 73-80, 2004.

FOUCAULT, M. História da sexualidade III: a vontade de saber. Rio de Janeiro: Graal, 1985.

MACHADO, R. Por uma genealogia do poder. In: FOUCAULT, M. Microfísica do poder. Rio de Janeiro: Edições Graal, 1998.

RAMOS, C. Reflexões sobre a formação de psicólogos em tempos de cinismo. In: _. Formação de psicólogos e relações de poder. São Paulo: Casapsi, 2012.

ROZENDO, A. S. Construção social do envelhecimento e experiências da velhice. 2010. 106 f. Dissertação (Mestrado em Psicologia) - Universidade Estadual Paulista, Faculdade de Ciências e Letras, Assis, 2010.

Recebido em: 02/01/2017

Aprovado em: 06/03/2017 